Accepted for publication in: Journal of Pragmatics (2017)

\title{
Institutional invitations to a meeting: Cold calls to bank clients
}

\section{Elwys De Stefani (KU Leuven)}

Abstract: This article analyzes unsolicited telephone calls in Italian, wherein employees of a bank telephone existing clients in order to arrange a consultation at the bank. The study documents two techniques with which callers attempt to secure appointments: (i) they can convey an invitation to come to the bank as the reason for the call and subsequently disclose the purpose of the meeting (formulation format); or (ii) they can first report an event concerning the client and then attempt to organize a meeting (solicitation format). In the first format the invitation is proffered with a declarative clause, in the second format with an interrogative clause. Acceptance of invitations tends to occur early after the solicitation format and late in response to the formulation format. Conversely, rejection of the invitation occurs early after the formulation format vs. late in response to the solicitation format. Institutional invitations are done in the service of another objective, namely selling new services; the project of arranging an appointment is abandoned if clients accept to sign up for specific services. Using conversation analysis, this article illustrates how the ordering of actions and the choice of grammatical patterns are consequential for clients' responses to institutional invitations.

Keywords: Institutional invitations; Cold calls; Formulation format; Solicitation format; Italian; Conversation analysis

\section{Introduction: Arranging a meeting at the bank}

Cold calls, in which salespeople solicit potential customers without prior contact, are an important part of telemarketing practice; and, of course, receiving such calls is a common experience for all telephone users. Whereas callers pursue the aim of selling a good or service, call-takers often experience unsolicited calls as annoying. Hence callers run the risk of encountering resistance, which may result in the rejection of the proposed deal. In the cold calls analyzed here, a bank employee calls existing clients in an attempt to arrange a meeting at which the client will be presented with tailored bank products. The expected upshot of these meetings is to get clients to sign up for specific financial services. Hence, bank employees pursue a twofold goal: indeed, a telephone call is successful if clients either accept the invitation to the consultation at a local branch of the bank, or agree right away to sign up for specific bank services without the need for a meeting.

Callers recurrently use two different practices to invite clients to the bank: either they use the verb invitare 'to invite', as illustrated in excerpt 1 , or they ask a question (excerpt 2 ). 
Ex. 1 (obfc6, 00:07-00:18) ${ }^{1}$ - The formulation format

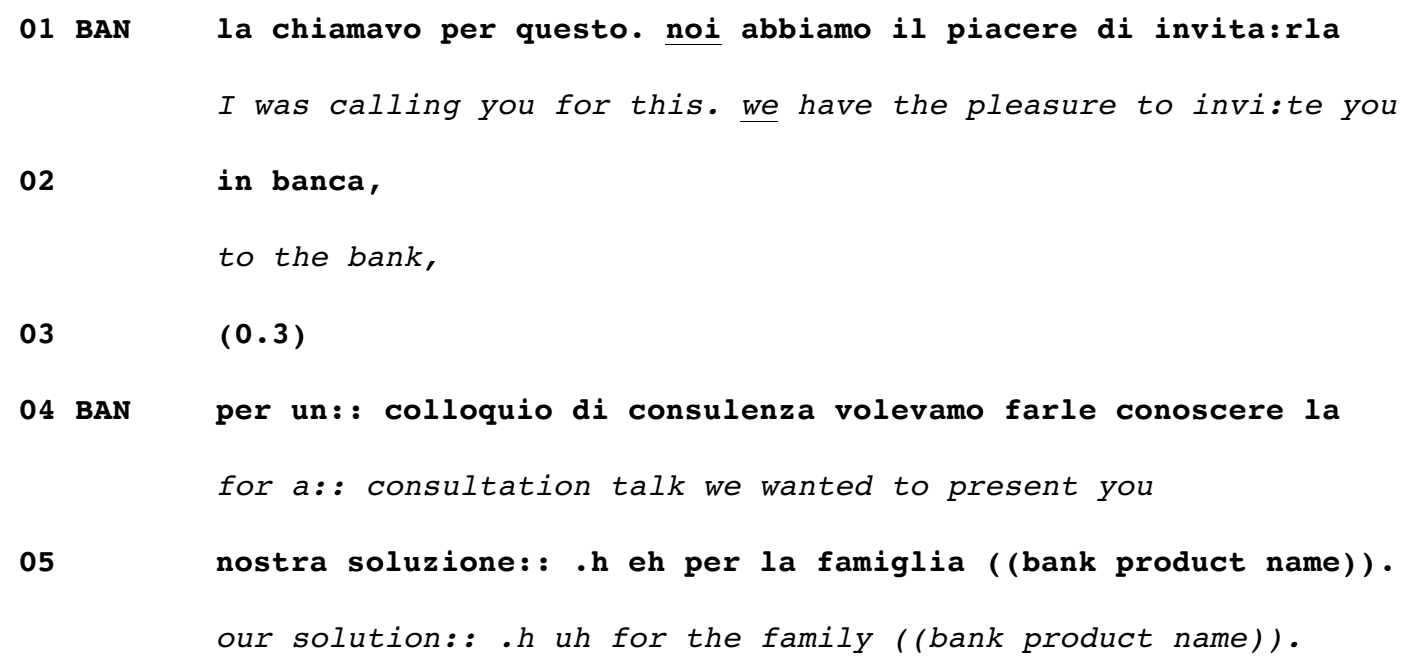

This excerpt shows a format occurring immediately after the opening sequence, in anchor position (Schegloff, 1986), which is hence proffered as the reason for the call. The bank employee (BAN) first conveys the invitation (I. 01-02) and then introduces the purpose of the invitation-i.e., a consultation talk in which financial services will be presented (I. 04-05). It is grammatically structured as a declarative clause. Henceforth, I will speak of the formulation format when referring to this technique. Conversation analytic literature has mainly focused on formulation as a recipients' practice, by which the latter provide a version of what another member has just said or done (Garfinkel and Sacks, 1970; Heritage and Watson, 1979). For the purposes of this article, a formulation is a practice whereby speakers explicitly articulate what they are doing. ${ }^{2}$ The second technique is associated with differing sequential and turnconstructional features.

Ex. 2 (obfc7, 01:15-01:21) - The solicitation format

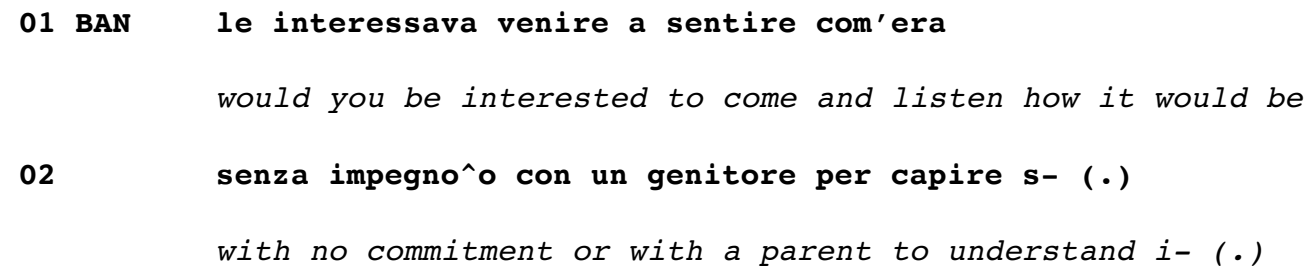

This format occurs later in the conversation: the caller has previously cited the client's upcoming birthday as the reason for calling. On the client's birthday, the services offered by the bank will change; some will no longer be available to the client, whilst other news one will

\footnotetext{
${ }^{1}$ I use the Jeffersonian conventions for the transcription. A circumflex accent $\left(^{(}\right)$is used to indicate linking of sounds between two units of talk.

2 This use is reminiscent of Conein's (1987:41) notion of quasi-formulation, which the author uses for invitations that speakers articulate with the verb 'to invite'.
} 
be. BAN has described these new products and services, and now invites the client to the bank, using an interrogative clause. BAN's interrogative clause is designed and treated as a first pair part, hence the label solicitation format for this technique. ${ }^{3}$

Within conversation analysis, the notion of format is primarily used with reference to the grammatical shape of turns-at-talk whereby speakers accomplish specific actions (e.g. requests, instructions). But "what exactly counts as a format" (Fox and Heinemann, 2016:502) remains an open question. The authors suggest that "the notion of format covers a much wider, more varied and much finer-grained composition of grammatical practices than has previously been described" (p. 526), thereby zeroing in on grammatical micro-variations of turns-at-talk. A further use of the term relates to the specific speech-exchange system (e.g., ordinary conversation vs. interviews) by which participants organize turn-taking (Peräkylä and Silverman, 1991) and is hence more concerned with how participants organize turn distribution. In this article, I use format to capture recurrent grammatical, but also sequential features of the actions BANs accomplish when inviting CLIs to a meeting. The two formats observed in my data show the following characteristics:

\section{Formulation format}

Sequential features:

1. Invitation in anchor position

2. Purpose of the invitation as turn extension

Turn-constructional features of the invitation:

Verb 'to invite' is used; declarative

\section{Solicitation format}

1. Report of a CLI-related event in anchor position

2. Invitation as new action

Verb 'to invite' is not used; interrogative

This article analyzes how callers employ these formats and how call-takers respond to them. I show that if callers use the formulation format $(\S 4)$, rejection of the invitation tends to occur early (§ 4.1), whereas acceptance occurs later in the conversation (§ 4.2). Conversely, if they

\footnotetext{
3 On one occasion, BAN says io avrei bisogno di pas- fissare con lei un appuntamento, 'I would need to pas- make an appointment with you,', thereby using what we might call a personal deontic declarative - as opposed to the impersonal deontic declaratives discussed by Rossi and Zinken (2016). In that case, too, BAN starts the call by congratulating the client on her 18th birthday (as in the other instantiations of the solicitation format). Reaching the age of majority has a series of legal consequences for the relationship that the client has with the bank. BAN explains that the client has to sign specific documents by law, otherwise her bank account will be blocked. Rejecting the appointment is thus not an option, and this makes the 'soliciting' quality of BAN's turn even more tangible.
} 
use the solicitation format $(\S 5)$, acceptance of the invitation tends to occur shortly after ( $\S$ $5.1)$, whereas rejection occurs later $(\S 5.2)$. Participants may reverse their initial responses: whereas call-takers can be seen to transform an initial accepting response into a final rejection of the invitation ( $\S 6.1$ ), callers systematically work toward reversing an initial rejecting response in order eventually to obtain acceptance of the invitation (§6.2).

By examining how bank agents invite clients to a meeting and how the latter accept or reject such invitations, this article shifts the perspective from ordinary social invitations to institutional invitations, and contributes to recent research on the management of successful institutional telephone calls (Stokoe, 2013; Sikveland and Stokoe, 2016), especially on cold calls and telemarketing practices (see Mazeland, 2004).

\section{Data and method}

The data were collected by the bank as part of routinely recorded telephone conversations between bank employees and clients. They consist of thirteen cold calls made by two bank employees who contacted existing clients of the bank in order to arrange a meeting and to present client-tailored services. Following the opening sequence, the formulation format is used in six calls, whereas the solicitation format occurs in four calls. The remaining three calls were terminated prematurely-i.e., before the reason for the call is introduced (because of recipient's unavailability). The interaction is recognizable as a business (Varcasia, 2013) or institutional (Drew and Heritage, 1992) conversation, among other things because participants exhibit their professional and client identities respectively. However, although the participants make relevant a standardized relational pair (Sacks, 1972) of the 'inviter'-'invitee' kind, the bank employee will not take part in the meeting to which she is inviting the client, which will involve a representative of the bank working in the client's area of residence. In the light of the differences between ordinary vs. institutional invitations, I will examine more closely how the latter are interactionally accomplished, conversation analysis (Sacks et al., 1974; Sacks, 1992) being the method of investigation.

\section{Previous research on invitations}

Invitations are frequently invoked in conversation analysis as illustrating the concept of an adjacency pair, consisting of an invitation/acceptance or rejection (Sacks et al., 1974:716), with acceptance being the preferred response to an invitation (Davidson, 1984:105). However, research on ordinary invitation sequences (Drew, 1984) has shown that invited speakers seldom overtly accept or reject an invitation in the following turn and that speakers often provide subsequent versions (Davidson, 1984) of the invitation as they pursue its acceptance (see also Davidson, 1990). For this reason, Quéré (1987:102) notes, "as a 
conversational event, an invitation never reduces to a pair-type of utterances or actions such as offer/acceptance or rejection." 4

While there is general agreement on conceptualizing invitations as initiating actions, authors tend to describe and hence to label the action that inviting speakers accomplish in sometimes strikingly different ways. For instance, Drew (1984:133) mentions the analytical category of invitation/proposal, whereas for Davidson $(1984,1990)$ invitations have similar sequential features to offers, requests and proposals. More recently, and on the basis of recurrent grammatical patterns, Couper-Kuhlen (2014:639) conceptualizes invitations as offers, and distinguishes these from suggestions and proposals. While trying to create taxonomies of actions (Searle, 1976; Couper-Kuhlen, 2014:628) inevitably goes hand in hand with difficulties in categorizing and labeling actions, it obliges the researcher to grasp the essential features of single social actions. For example, according to Schegloff (2007:82), both requests and offers deal with "the transfer of something of value", whereas CouperKuhlen (2014:628) describes offers (including invitations) as actions that generate "costs accruing to the initiator but benefits accruing to the recipient" (see also Clayman and Heritage, 2014).

In ordinary conversation, acquainted speakers overwhelmingly do not formulate invitations as being invitations (Conein, 1986, 1987; Sacks, 1992 II:367). Invitations rather provide partial descriptions of an event (Sacks, 1992 II:367-369), which may be produced with a declarative (I'll buy you a cup of coffee), an imperative (Come and have coffee) or an interrogative (Why don't you come over for coffee) clause (see Drew, 1992:498; Clayman and Heritage, 2014:61). Also, speakers can use the reporting of events as grounds for making invitations, offers, etc. (Drew, 1984). On occasion, however, speakers do formulate their action as being an invitation-e.g., by using the verb 'to invite'. This use is documented in the cold calls analyzed here. The ordinary practice of 'inviting' is used here for the purpose of making clients sign up for new products. As in other kinds of institutional interaction, invitations of this sort run the risk of encountering resistance (see Stokoe, 2013; Sikveland and Stokoe, 2016).

\section{The formulation format}

In this format, the invitation occupies the first sequential slot available for introducing the reason for the call. Callers first formulate the invitation and subsequently provide additional information on the purpose of the invitation by incrementing their turn-at-talk. Whereas

\footnotetext{
4 "[E]n tant qu'événement conversationnel, une invitation ne se réduit jamais à une paire-type d'énoncés ou d'actions du genre offre/acceptation ou refus."
} 
rejecting responses may occur soon after the caller has introduced the purpose of the invitation (excerpts 3-4), accepting responses (excerpt 5) tend to occur later.

\subsection{Rejection following the formulation format}

The first point at which clients may reject the bank's invitation is located after the caller has mentioned the purpose of the invitation. The following fragment (presented earlier as excerpt 1) illustrates a case in point.

Ex. 3 (obfc6, 00:07-00:21)

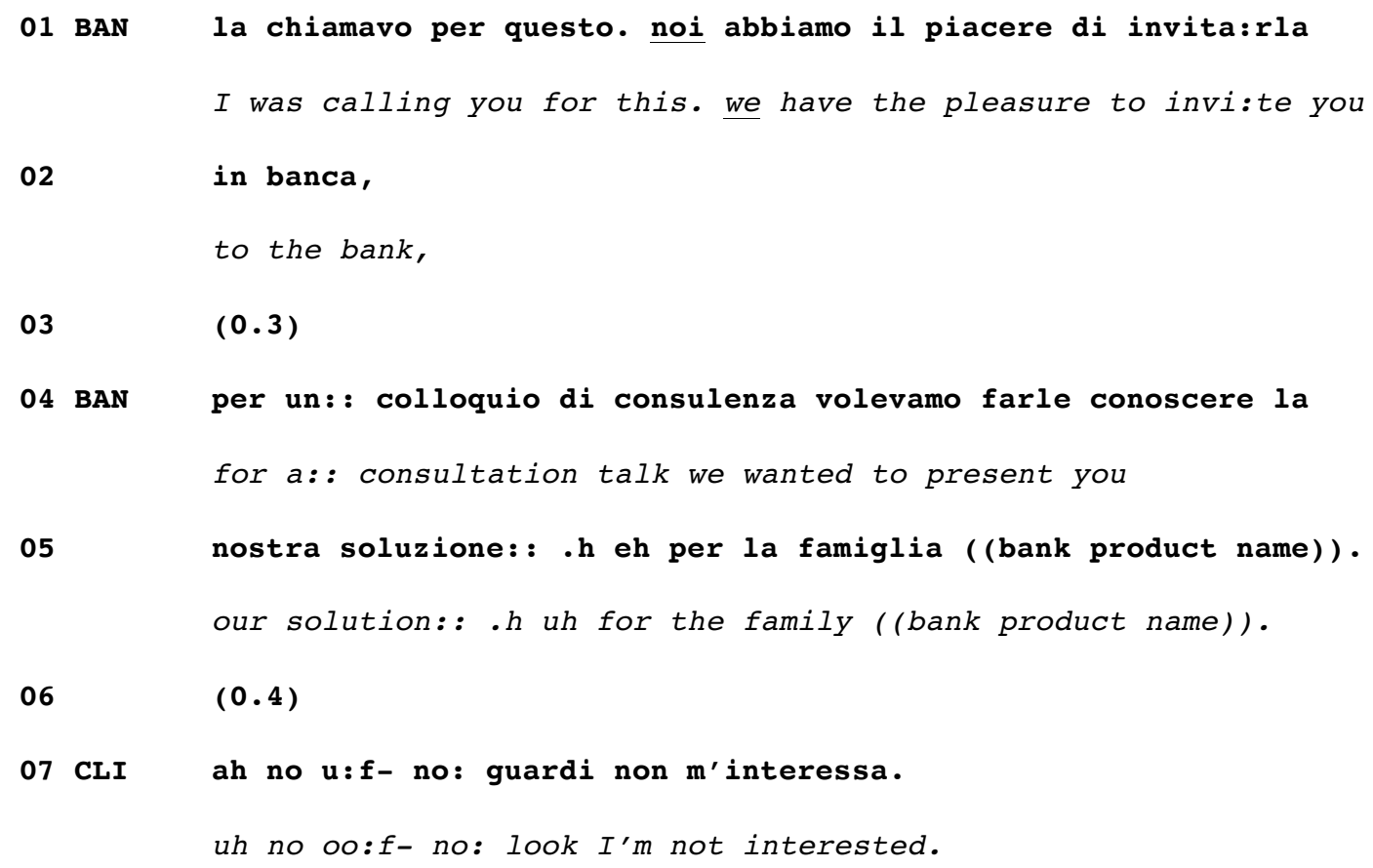

BAN first formulates the invitation (I. 01-02) as the reason for the call (la chiamavo per questo. 'I was calling you for this.'). The turn is recognizable as a declarative at the end of I. 02, but the continuing intonation on banca, 'bank,' projects continuation of the turn. BAN briefly suspends her turn (see the pause at I. 03), but CLI does not treat this moment as an opportunity to accept or reject the invitation. BAN then increments her turn (see CouperKuhlen and Ono, 2007) and spells out the purpose of the invitation (I. 04-05), i.e., a 'consultation talk' during which the client (CLI) would be presented with certain bank products (I. 04-05). After a brief pause (I. 06), CLI rejects the invitation and accounts for that rejection by mentioning a lack of interest (I. 07). CLl's turn presents features that make it recognizable 
as doing a dispreferred action (ah no u:f- no:; 'ah no oo:f- no:'), namely rejecting the invitation. ${ }^{5}$ The rejection of the invitation will be the outcome of this conversation.

The following call starts in a similar way. BAN first formulates the invitation (l. 01-03) as a declarative. Again, a micropause occurs (I. 04), which shows that CLI expects 'more to come'. As in the previous case, BAN increments her turn and adds the purpose of the invitation (I. 05-06), which is uttered with a final intonation. At this point, CLI would have the sequential possibility to respond. After the pause at I. 07, CLI produces instead the continuer $m h m$ (I. 08).

Ex. 4 (obfc2, 00:11-00:47)

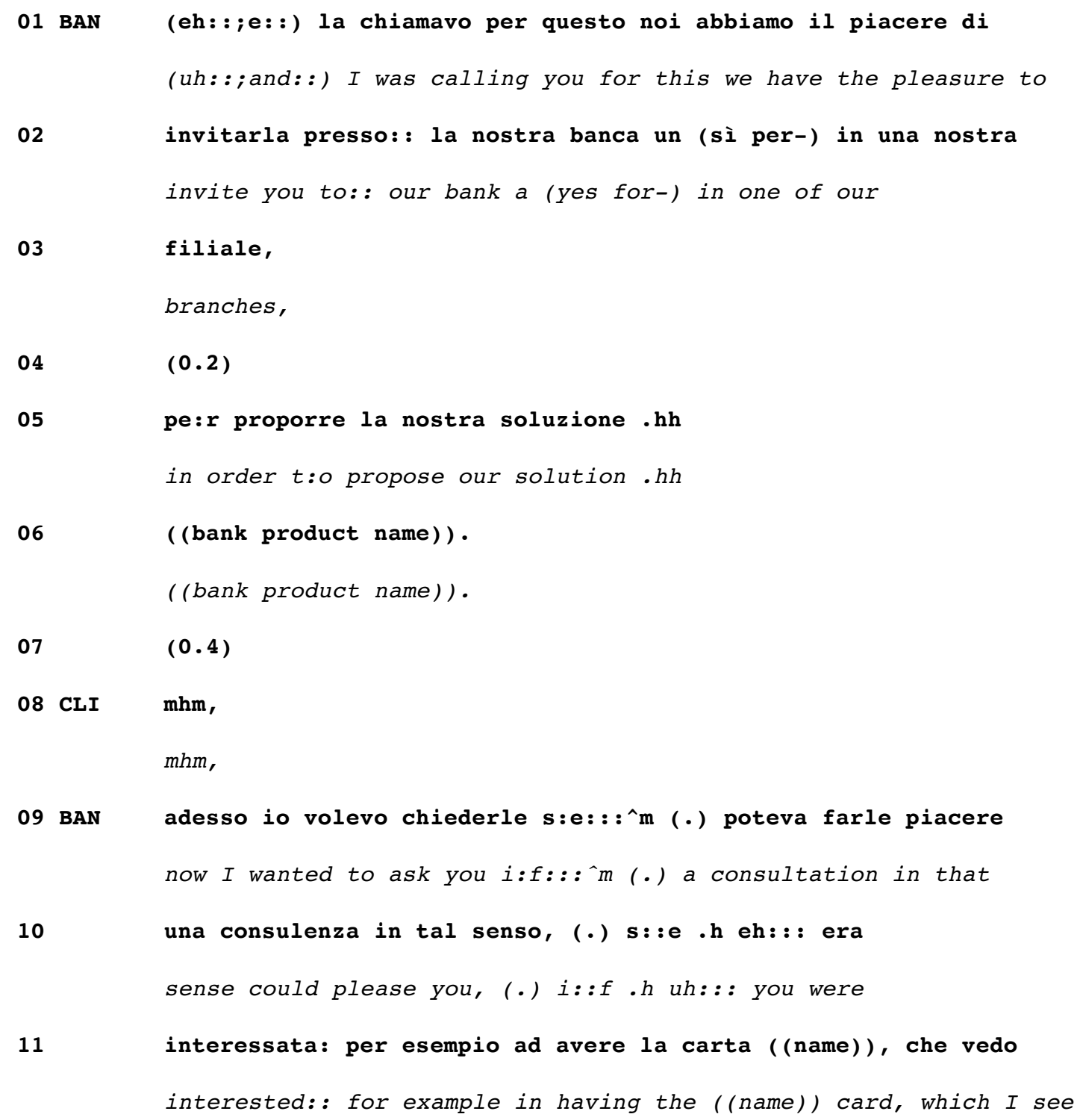

\footnotetext{
${ }^{5}$ Although the pause at I. 06 could be described as a pre-rejection silence in Davidson's (1984:152) terms, the analysis of the subsequent excerpts shows that pauses regularly occur at this position, even in those invitations that are followed by acceptance (see $\S 4.2$ and $\S 5.1$ ).
} 


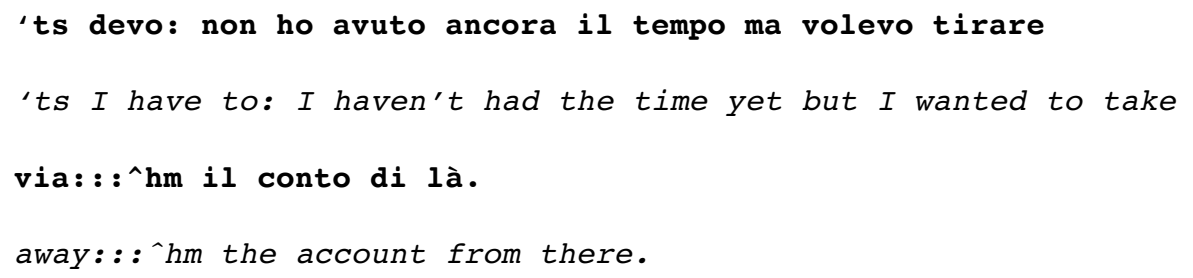

At I. 09-12 BAN shapes her talk as a new turn (rather than as an increment), and as a different action: she produces an indirect interrogative (volevo chiederle 'I wanted to ask you', I. 09) about whether a consultation talk would 'please' CLI and whether she would be interested in having a specific bankcard. By using an interrogative, BAN employs a resource that is regularly found in the solicitation format. As I will show in $\S 5$, interrogatives set up a much more stringent projection. The initial invitation in the formulation format (abbiamo il piacere di invitarla 'we have the pleasure to invite you', I. 01-02) is presented and treated as an announcement projecting 'more to come', and is regularly followed by a pause and/or a continuer by CLI (excerpt 3, I. 03; excerpt 4, I. 04). However, the action that BAN initiates at I. 09 instead projects acceptance or rejection of the invitation as an appropriate next answer. And this is precisely what CLI does as she starts her turn with no, then citing her lack of interest (I. 13-14), as CLIs do in other cases (see e.g. excerpt 3); in this case CLI adds to her rejection that she was planning to 'take away::.^hm the account from there.' (I. 17-18)-i.e., to cease her relationship with that specific bank.

Call-takers treat formulated invitations (excerpt 3, I. 01-02; excerpt 4, I. 01-03) as announcements of further talk by BAN. A first sequential occasion for CLI to respond occurs after BANs have introduced the purpose of the invitation. If that occasion is not taken, BANs elaborate on their turn, thereby providing a next occasion to respond (excerpt 4). Noticeably, BANs use similar lexical, grammatical, and pragmatic resources across the excerpts analyzed so far. This shows that they employ a formal script, which, however, has to be adjusted to CLIs' locally emerging responses. I have so far looked at cases in which CLIs 
respond with a rejection. In the previous literature on ordinary invitations, rejection has been described as a dispreferred action (Davidson, 1984). This is confirmed by the institutional data analyzed here, where rejections may be produced with turn-design features of dispreference (excerpt 3), and are always accounted for. In ordinary invitations, speakers may reject an invitation in different, more or less overt ways. For instance, they may respond with an initial weak agreement that is "possibly rejection-implicative" (Davidson, 1984:112), or "report some circumstances or activities, without concluding what the report's upshot is for the invitation/proposal" (Drew, 1984:146), hence encouraging the inviter to recognize that acceptance is not an option. In institutional invitations, CLls present rejection overtly as such, e.g., by starting their turn with the negative particle no (excerpt 4 ; ah no in excerpt 3 ). Although both participants exhibit their orientation toward rejection as being dispreferred, CLIs may nonetheless legitimately produce it overtly and early in the course of the conversation. Instead, acceptance occurs late, as I show in the following section.

\subsection{Acceptance following the formulation format}

In the next excerpt, BAN repeatedly puts briefly on hold her turn-in-construction, thereby offering CLI successive opportunities to respond. By doing so, BAN cautiously checks whether the recipient is available not only for the institutional conversation at hand, but also to accept an appointment. In this case, CLI produces continuers over a long conversational episode.

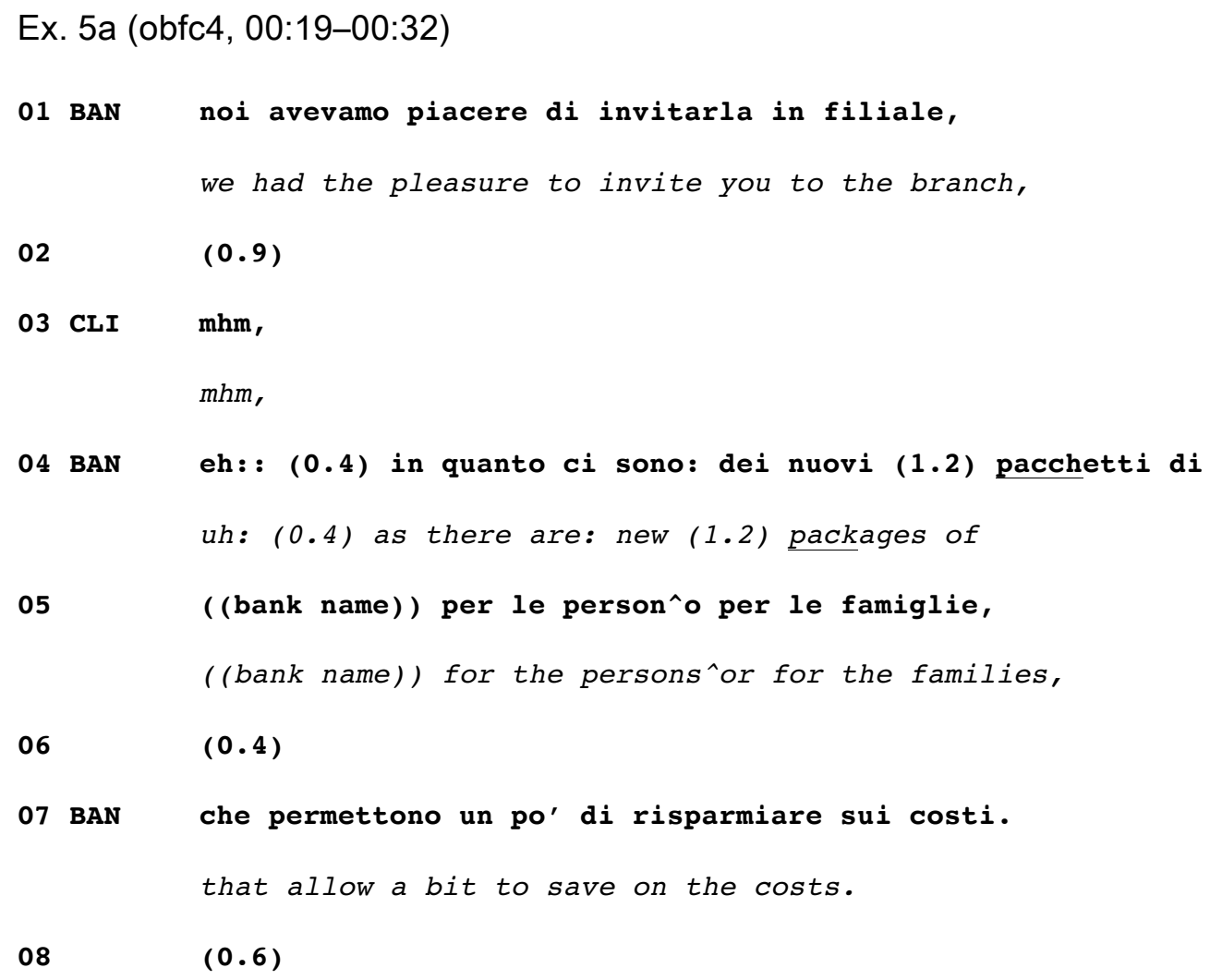


09 CLI [

$[\mathrm{mhm}$,

Here, BAN employs the same resources observed earlier. She starts by formulating an invitation, which is shaped with a continuing intonation projecting 'more to come'. She pauses her turn (I. 02) and extends it as soon as CLI produces a continuer (I. 03). BAN subsequently mentions the reason for the invitation-i.e., the availability of new bank products (I. 04-05). Again, BAN pauses her turn (I. 06), thereby offering CLI an opportunity for responding, which he does not take. BAN further increments her turn, now introducing a possible benefit for CLI ('saving on the costs'; I. 07). She ends her turn with a final intonation, thereby recognizably creating an opportunity for response. CLI again produces a continuer (I. 09), in overlap with BAN, who starts a new turn.

Ex. 5b (obfc4, 00:32-00:50)

10 BAN [questi-

[these-

11

$(0.8)$

12 BAN

questi:: pacchetti sono composti non: non si parla

these: : packages are composed not: we're not talking about

13

d'investimenti sono composti da: (.) conto privato conto

investments they're composed of: (.) private account savings

14

risparmio e l'utilizzo delle carte, che lei ha già.

account and the use of the cards, which you already have.

15

$(0.6)$

16 CLI $\mathrm{mhm}$,

$\mathrm{mhm}$,

17 BAN però invece di pagare la tassa, con un: forfait mensile, but instead of paying the fee, with a: monthly flat rate,

18

(.) si risparmia un po' sul costo.=quindi serve (.)

(.) one saves a bit on the cost.=so it serves (.)

19

${ }^{\circ} \mathrm{un}^{\circ}$ po' per ottimizzare.

${ }^{\circ} a^{\circ}$ bit to optimize.

20

$(0.5)$

$21 \mathrm{CLI} \mathrm{mhm}$,

$m h m$, 
At I. 12, BAN provides additional information about the 'packages' that she is trying to sell, thereby making understandable the purpose of the meeting. She also adds empirical details about CLI when she mentions that he 'already has the cards' (I. 14). Her turn is possibly complete, and is again followed by a pause (I. 15) and a continuer from CLI (I. 17). At this point, BAN further extends her turn (I. 17-19) and spells out the potential benefit to CLI of the new packages (I. 17); BAN presents this as an 'optimization' (I. 19) of the bank services that CLI already enjoys. This is a further opportunity for CLI to respond in some way, but he again produces a continuer (I. 21). Subsequently, CLI initiates a side sequence (Jefferson, 1972) in which he asks BAN where she is calling from (not reproduced) and the participants briefly talk about the fact that CLI is now living in a city other than the one in which he opened his account some years ago. The conversation continues thus.

Ex. 5c (obfc4, 01:00-01:18)

((12 lines omitted))

34 BAN quindi magari avevamo il piacere di invitarla

so possibly we would have the pleasure to invite you

35

a ((place name) )?

to ((place name))?

$36 \quad(0.5)$

$37 \mathrm{CLI} \quad \mathrm{mh}[\mathrm{m}$,

$m[h m$,

38 BAN

[così: (.) i colleghi-conosceva i colleghi

[so:: (.) the colleagues- you'd get to know the colleagues

39

di ((place name))?

of ((place name))?

40

$(0.4)$

41 CLI ce [rto

su $[$ re

42 BAN [e:: (.) e aveva l'opportunità di avere anche lì un punto [and::: (.) and you'd have the opportunity to have there 
BAN's turn at I. 34-35 is recognizably reformulating the invitation proffered at I. 01 . BAN formats this second formulation differently, as an interrogative, as the final rising intonation shows. ${ }^{6}$ Moreover, BAN takes up the matter discussed in the preceding side sequence by formulating an invitation to a meeting in CLl's current area of residence. Both the interrogative format of BAN's turn and the fact that its content is based on empirical evidence concerning CLI are features that are seen in the solicitation format ( $\S 5$ ). By using an interrogative, BAN produces a first pair part, making relevant completion of the sequence in the next turn. In this case, however, CLI again produces a continuer (I. 37). In overlap, BAN extends her question and adds additional grounds for CLI to accept the invitation. BAN's turn extension (I. 38-39) strongly projects agreement: indeed, on the basis of the empirical details that BAN has proposed, it would be difficult for CLI not to agree that an appointment would allow him to meet the agents working in his current place of residence. And an agreement is indeed what CLI produces at I. 41, as BAN's subsequent turn extension shows (I. 42-44): she clearly treats CLI's certo 'sure' (I. 41) as agreeing with the previous action, rather than accepting an invitation. Her turn extension (I. 42-43) further pursues acceptance. CLI produces again the token $\mathrm{mhm}$ (I. 46), but BAN does not treat it as a continuer, as the pause at I. 47 shows. It is after that pause that CLI accepts the invitation with the words si perché no. 'yes why not.' (I. 48). ${ }^{7}$

The analysis of this excerpt shows that acceptance of the invitation occurs late in the formulation format. BAN has evidently succeeded in 'securing' the CLI, who repeatedly produces continuers following BAN's multiple turn extensions. But it is only when BAN relates the invitation to empirical circumstances concerning CLI and when she adopts an

\footnotetext{
6 In Italian, prosody is paramount for distinguishing declarative from interrogative constructions; see Rossano (2010) for a discussion.

7 Whereas from a strictly formal perspective, the wording si perché no 'yes why not' (I. 48) could be analyzed as exhibiting less commitment than an isolated si 'yes', a sequential analysis identifies CLI's acceptance of the invitation precisely in this turn. Indeed, a simple si, 'yes' at this sequential position could have been heard as an acknowledgment token (see excerpt 8a, I. 11 for a case in point), rather than as acceptance of an invitation.
} 
interrogative, rather than a declarative turn-format, that CLI moves toward accepting the invitation. Both of these aspects are present from the onset in calls in which BAN uses the solicitation format.

\section{The solicitation format}

As we have seen, BANs cite the client's birthday as the reason for calling, explaining that this will change the arrangements the client has with the bank. In these cases, BANs only subsequently attempt to arrange a meeting, and they use interrogatives to do so. When they use this procedure-i.e., the solicitation format-acceptance tends to occur soon after the invitation has been proffered, whereas rejection tends to occur late.

\subsection{Acceptance following the solicitation format}

The following call has started with BAN congratulating CLI on her upcoming $20^{\text {th }}$ birthday. She has explained that CLI will therefore no longer be able to enjoy the preferential terms offered to younger clients. She then asked CLI whether she knows the packages that the bank recommends to clients her age, and CLI has confirmed that she does know those packages because she has just received corresponding information material from the bank. The conversation continues as follows.

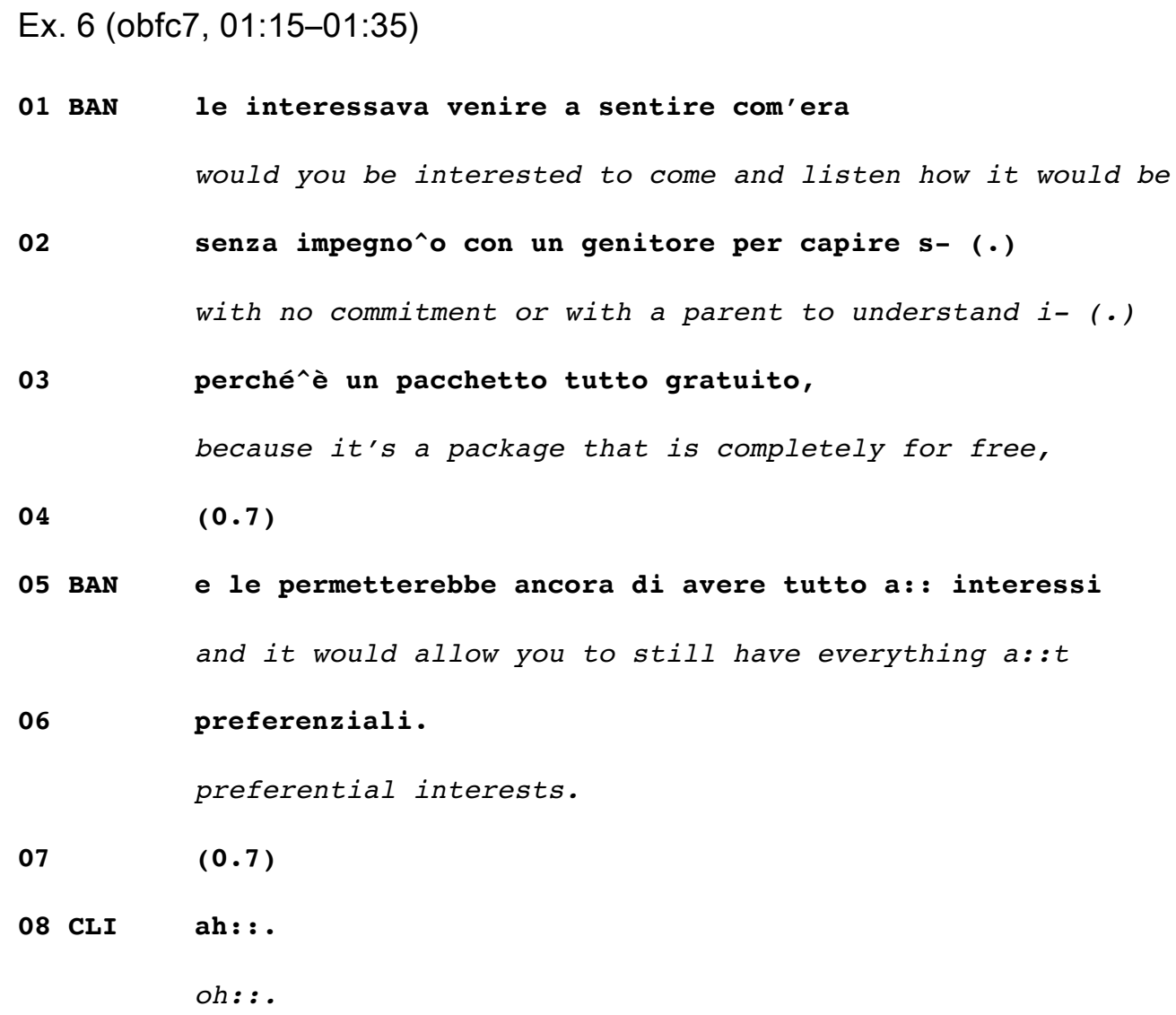


09

$10 \mathrm{CLI}$

11

12 BAN

13 CLI

14 BAN

15
$(0.4)$

ma non posso dirle già che mi va bene perché ho letto.

but can't I already tell you that it's okay for me because I've read.

$(0.3)$

le va bene?

is it okay for you?

sì: pe[rché ho già letto: :

yes: be[cause I've already read: :

[io le posso mandare tutto a ca-. se lei è inte-

[I can send you everything ho-. if you're inte-

lei che scuole frequenta?

what school are you attending?

The excerpt starts with the first turn in which BAN mentions the possibility of a meeting at the bank. In this case, BAN uses a yes/no interrogative (Raymond, 2003) and asks CLI if she would be interested 'to come and listen how it would be' (I. 01). She extends her turn by adding that the meeting does not imply any commitment from CLI and that she can come with a parent (I. 02). The TCU at I. 02 remains syntactically incomplete, as BAN produces a restart, which allows her to introduce a benefit that CLI could enjoy: the package she is talking about is 'completely for free,' (I. 03). Although the intonation on the last unit of this TCU is continuing, BAN pauses (I. 04), possibly providing a slot for CLI's response. She then extends her turn by adding a further benefit that CLI could enjoy if she were to sign up for the package, this time ending her TCU with a final intonation (I. 05-06). After a further pause (I. 07), CLI responds first with a lengthened $a h: .$. 'oh:.:' (l. 08) and shortly after with an alternative solution, consisting in accepting the new bank product without having a consultation talk (I. 10). CLI's ah:: (I. 08) and the unit ma 'but' placed at the turn-beginning (I. 10) show that her response is dispreferred, in the sense that it is not type-conforming (Raymond, 2003:946). Indeed, CLI accounts for her alternative answer by saying that she has 'already read' the brochure that the bank has sent her and that was previously mentioned (not reproduced). At I. 12, BAN formulates a confirmation request by recasting CLI's own words (le va bene? 'is it okay for you?'), to which CLI responds with si: 'yes:' and a repetition of her previously mentioned account (I. 13). BAN self-selects in overlap, with a turn accepting this alternative solution (I. 14).

Note that BAN could have treated CLI's alternative solution (I. 10) as rejecting the invitation. The fact that she does not make the consultation talk relevant any more shows that her 
ultimate aim is to sell bank packages, whereas the consultation talk is just one possible way in which that aim can be achieved. By proposing an alternative solution, CLI exhibits precisely her understanding of the meeting as being arranged in order to modify existing contracts with the bank. From BAN's perspective, then, this is a successful outcome and therefore a successful conversation.

The following excerpt starts in a similar way: BAN opened the conversation by congratulating $\mathrm{CLI}$ on his $22^{\text {nd }}$ birthday and then explained to him the consequences for his relationship with the bank. The conversation continues as follows.

Ex. 7 (obfc8, 01:18-01:34)

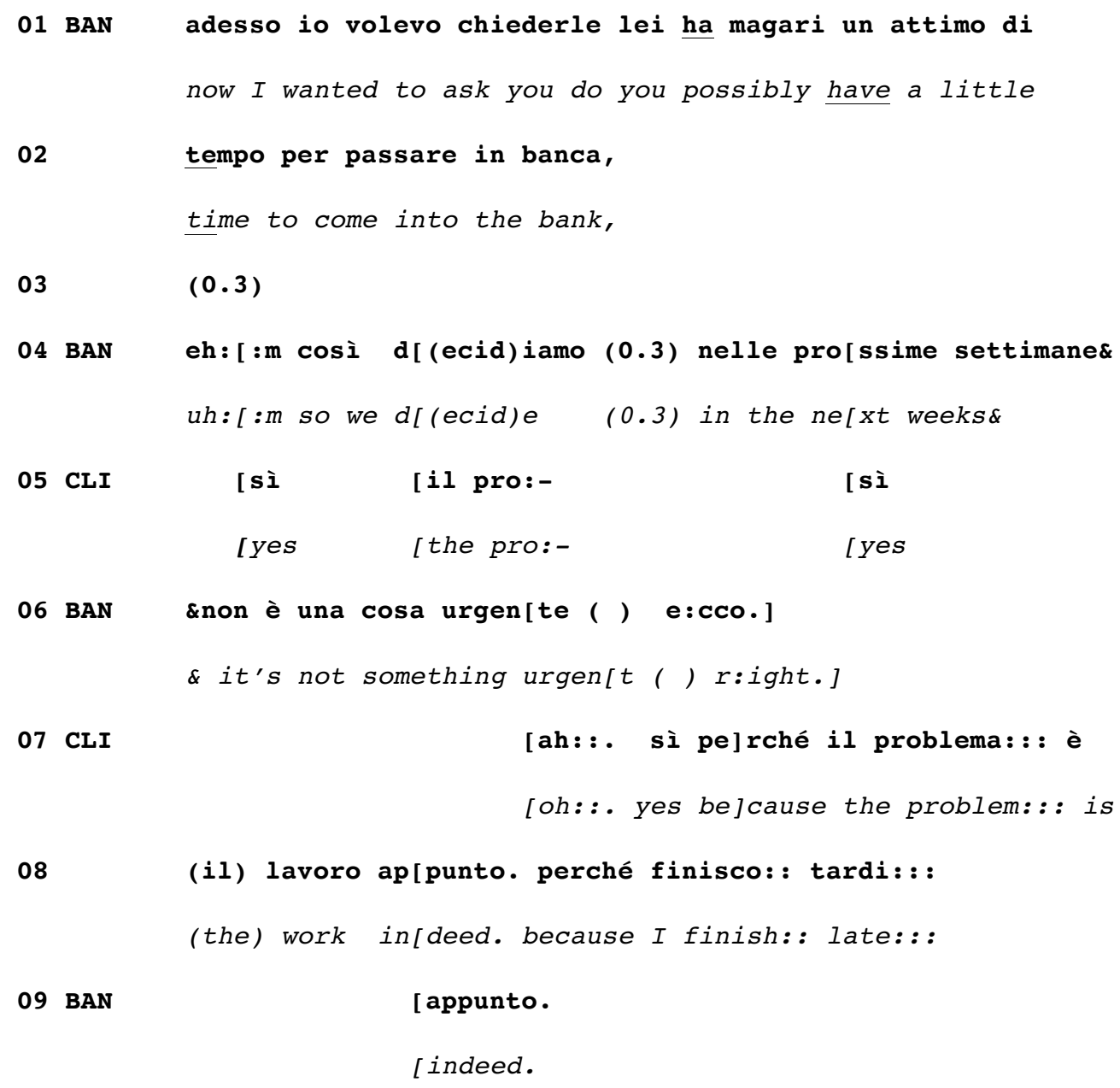

As in the previous excerpt, BAN produces a yes/no interrogative, asking CLI whether he has 'a little time' to 'come' to the bank (I. 01-02). BAN briefly suspends her turn (I. 03), thereby creating a slot for CLI to respond. At this point, BAN's turn is recognizable as a first pair part. While BAN starts extending her turn (I. 04), CLI provides a first answer (si 'yes', I. 05), and shortly after produces il pro:- (I. 05), which can be heard as a cut off instance of il problema 'the problem' (see I. 07). Notably, BAN herself makes relevant a possibly upcoming problem, 
when she says that CLI's visit to the bank can happen 'in the next weeks' (I. 04) and that it is 'not urgent' (I. 06). In this case, CLI has displayed initial acceptance of the offer to 'come into the bank' (I. 05) by uttering a si 'yes' in the sequential position that appropriately hosts a response to BAN's invitation. BAN no longer pursues a response to her invitation, and this is further evidence that she is treating CLI's si 'yes' as an acceptance. However, CLI presents his working late as potentially problematic for making an appointment (I. 07-08), thereby possibly putting at risk the agreed upon meeting. Indeed, the subsequent analysis of this call (excerpt 9) will show that CLI eventually draws back from the meeting.

\subsection{Rejection following the solicitation format}

CLIs tend to take more time before rejecting a meeting when the solicitation format is used. The following conversation starts again with BAN congratulating CLI on her $20^{\text {th }}$ birthday and informing her that the interest rates for the savings account she has at that bank will change. BAN has just asked CLI whether she is working or studying. CLI has replied that she does both and that her salary goes to an account run by another bank.

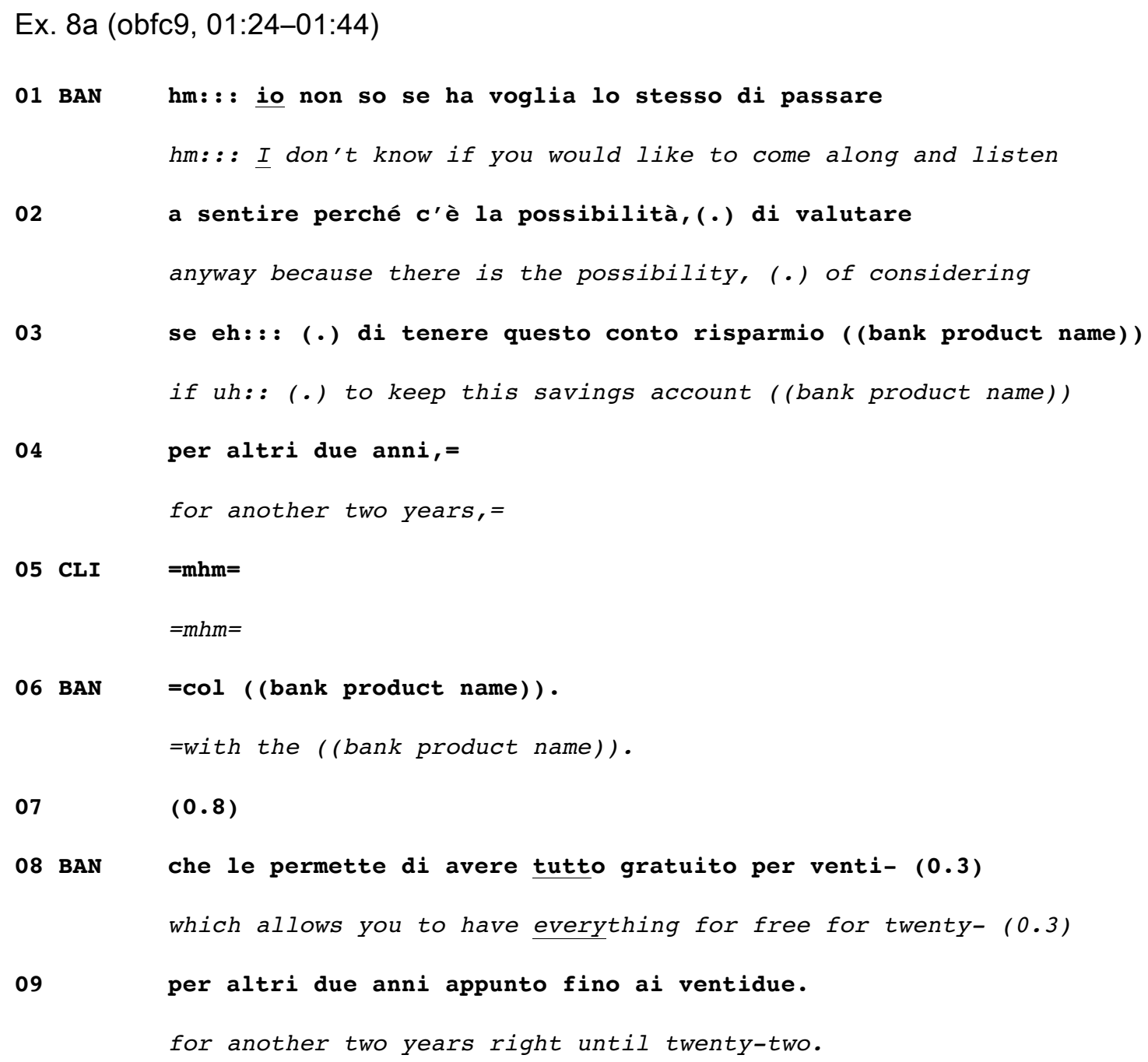




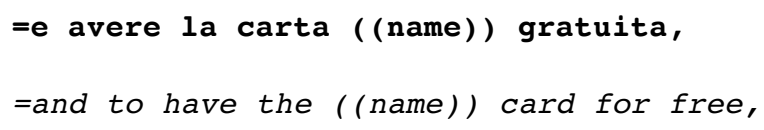

At I. 01-02, BAN produces a yes/no interrogative, asking CLI whether she would like to 'come along and listen'. BAN's turn starts with a lengthened $h m::$. that is followed by io non so 'I don't know' (I. 01), a resource that recalls Schegloff's (1996:61-62) prefatory epistemic disclaimers, which project 'more to come'. In this case, 'I don't know' is the recognizable beginning of a syntactic structure continuing with the conjunction se 'if'. BAN immediately extends her turn by adding the purpose of the meeting, consisting in evaluating whether CLI should keep her savings account for another two years (I. 02-04). At I. 05, CLI produces a continuer, after which BAN adds the name of the bank product with final intonation. Accordingly, I. 07 could host CLI's response, but CLI does not take this opportunity. BAN then increments her turn with a relative clause and adds a specific benefit of signing up for the service BAN is proposing-i.e., having 'everything for free' for another two years (I. 0809). She thereby creates a further slot that could host CLI's response. CLI produces a slightly stretched si: 'yes:' (I. 11), which BAN hears as an acknowledgment rather than as an acceptance of the invitation, as shown in her subsequent turn-extension with which she adds a further benefit for CLI (I. 12). At I. 12, BAN is thus still engaged in pursuing a response from CLI to her initial invitation. At I. 14, CLI produces another continuer, after which BAN adds further advantages that CLI would enjoy were she to accept the service proposed (not reproduced). In pursuing an answer, BAN proceeds in the same way we have already observed in excerpt 5-i.e., with successive turn-extensions detailing potential benefits for CLI. Similarly, the latter produces continuers and acknowledgements, thereby delaying her response. We join the conversation again just before CLI responds to the invitation.

Ex. 8b (obcf9, 01:53-02:02)

$$
\text { ( ( } 9 \text { lines omitted) ) }
$$

24 BAN

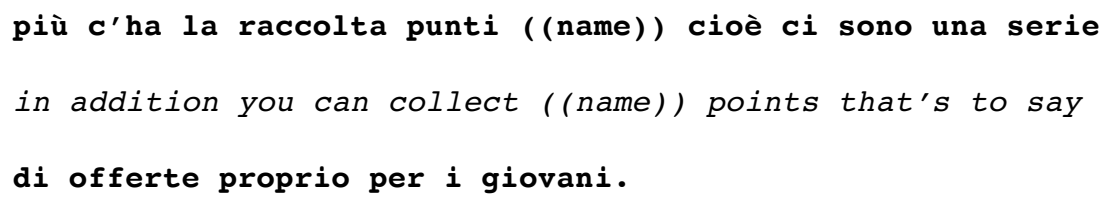


there's a series of offers precisely for young people.

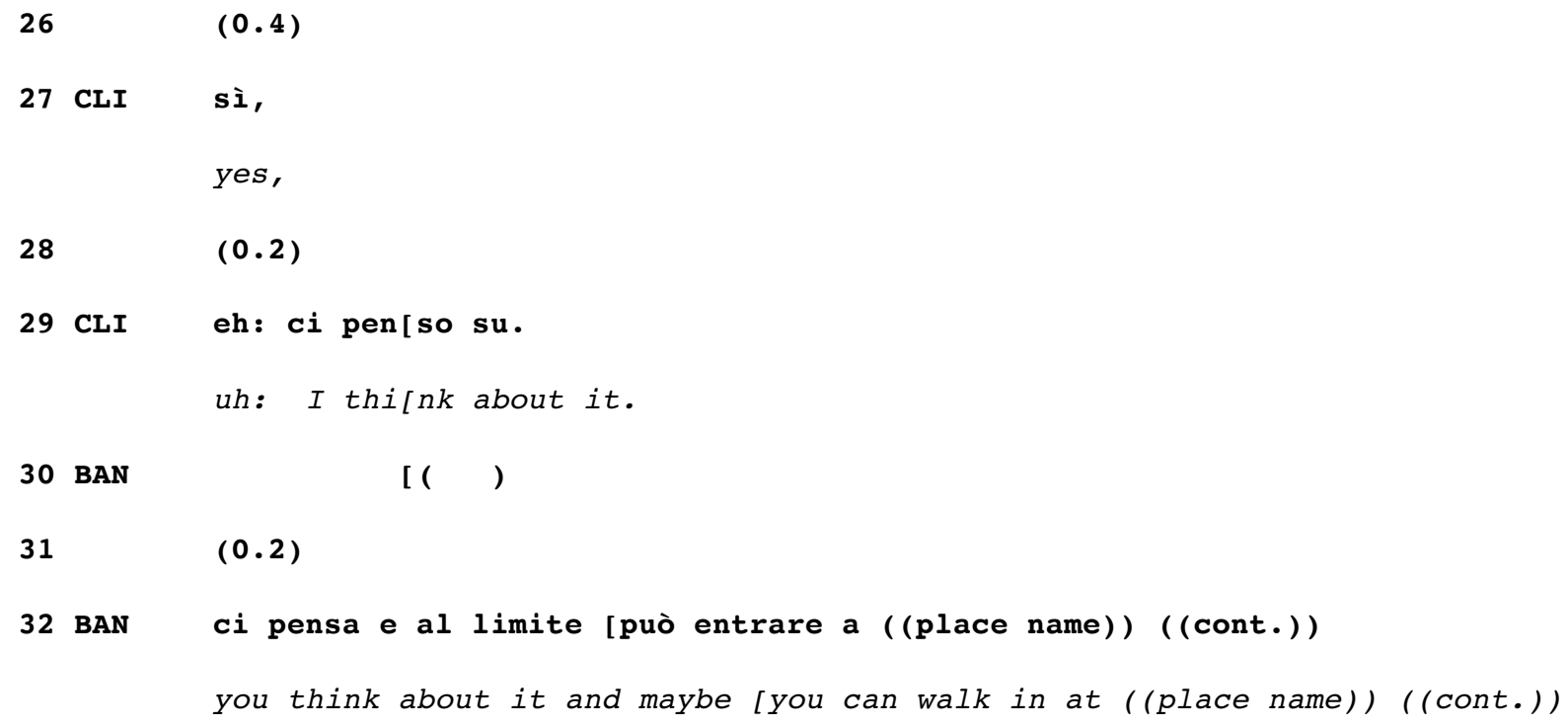

At I. 24-25, BAN describes a further advantage that CLI could enjoy with the proposed package, consisting of the possibility of collecting points as part of a loyalty program. CLI first acknowledges this information (I. 27) and then says eh: ci penso su. 'uh: I think about it.' (I. 29), where the turn-initial preface eh: makes a dispreferred answer expectable. Although CLI's answer is not type-conforming, BAN treats it as perfectly appropriate. She ratifies it and then recasts the possibility to discuss the issue with some agent at the local branch without any appointment (I. 32). CLI's choice to respond by saying that she will 'think about it' rather than overtly rejecting the invitation is one way of dealing with the delicate matter of declining a service that has been presented as entirely beneficial to her. The conversation ends less than ten seconds later without an appointment for a meeting having been made.

\section{Transforming the initial response}

Both BANs and CLIs have the possibility of modifying an initial acceptance or rejection of the invitation. CLIs who provide an initial accepting response may subsequently withdraw from their engagement, typically by exhibiting appointment scheduling problems. Conversely, when BANs receive an initial rejection from CLIs, they start working toward obtaining a subsequent accepting response, which is further evidence that rejection is a dispreferred response in institutional invitations. Hence, transforming initial acceptance into rejection is pursued by CLIs, whereas transforming an initial rejection into an acceptance is what BANs pursue.

\subsection{Accepting an invitation without commitment: A client's method}

CLIs' initial acceptance of the invitation sets off the conversation in a specific direction: at a certain point, the participants will need to make an appointment. The following fragment 
shows the continuation of excerpt 7 . CLI has initially accepted the invitation but he has also mentioned working late as a potential problem for arranging an appointment. More than a minute later, the participants have managed to find a week in which CLI would be available and BAN is now asking for a specific day in that week.

Ex. 9 (obfc8, 02:46-03:14)

69 BAN e: che giorno preferisce.

a: nd which day do you prefer.

$70 \quad(0.5)$

71 CLI hm: : :

$h m::$ :

72

$(1.8)$

73 BAN ${ }^{\circ}$ : : : : ${ }^{\circ}$ non so preferisce^l lunedì::

${ }^{\circ} n:::^{\circ} I$ don't know do you prefer Monday: :

74

$(0.4)$

75 BAN eh 1:: piuttosto che magari^l venerdì (fri-) o magari

uh: th: : rather than maybe Friday (fri-) or maybe

76

terminare [ ( $)$

end $[1$

77 CLI

[sì sì sì no no pure:: lunedì.

[yes yes yes no no also:: Monday.

78

$(0.2)$

$79 \mathrm{CL}$

però: : : adesso^l giorno la data precisa non gliela so dire.

but:: : now the day the precise date I cannot tell you.

80 BAN $[\mathrm{mhm}$

$[\mathrm{mhm}$

81 CLI [.hh magari: se mi lascia un numero telefonico: la richiamo: :

[.hh maybe: if you give me a telephone number: I call you

82

e fiss[iamo un appu[ntamento.

back: : and we [make an appoi[ntment.

83 BAN

$$
\begin{aligned}
& \text { [allo- [allora }(0.3) \text { se: } \mathbf{h m : :} \text { : se no se^eventualmente } \\
& \text { [okay- } \\
& \text { [okay (0.3) if: } h m:: \text { : otherwise if maybe }
\end{aligned}
$$


for you it's a problem let's do like this I send you all the

85

documentazione a casa.

documentation to your home.

BAN's question about the day on which the meeting might take place (I. 69) remains unanswered, as CLI's hm::: (I. 71) and the subsequent long pause (I. 72) show. BAN offers the candidate answers 'Monday' (I. 73) and 'Friday' (I. 75), after which CLI begins in overlap and mentions 'Monday' as a possible day (I. 77). However, he adds that he cannot give BAN a precise date (I. 79), thereby displaying that he is not at present able to arrange a date for the meeting. He then proposes an alternative way forward by asking BAN for a telephone number that he could call to make an appointment at a later time (I. 81-82). BAN does not treat this as a viable solution and suggests sending all the documentation about the bank's products to CLI's home address (I. 84-85). On the one hand, this is further evidence that BANs pursue a twofold goal-namely arranging a meeting and encouraging CLIs to sign up for specific bank products. If they encounter resistance in arranging the meeting, they may announce that they will send some paper documentation to CLI, who accepts this proposal in all the cases. On the other hand, the analysis shows that although CLIs may initially accept an invitation, the sequence dedicated to the arrangement of the meeting offers a last opportunity for CLIs to withdraw.

\subsection{Pursuing acceptance after initial rejection: A bank employee's method}

BANs never accept rejections of invitations upon their first occurrence. They systematically try to transform a first rejection into a final acceptance of the invitation, even in cases in which CLI initially displays vigorous rejection. In excerpt 4, for instance, CLI has not only rejected the invitation but also announced that she will 'take away' her money from the bank. She then explains that the activity fees she has to pay whenever the money on the account falls below a certain threshold are too high (not reproduced). The conversation continues as follows.

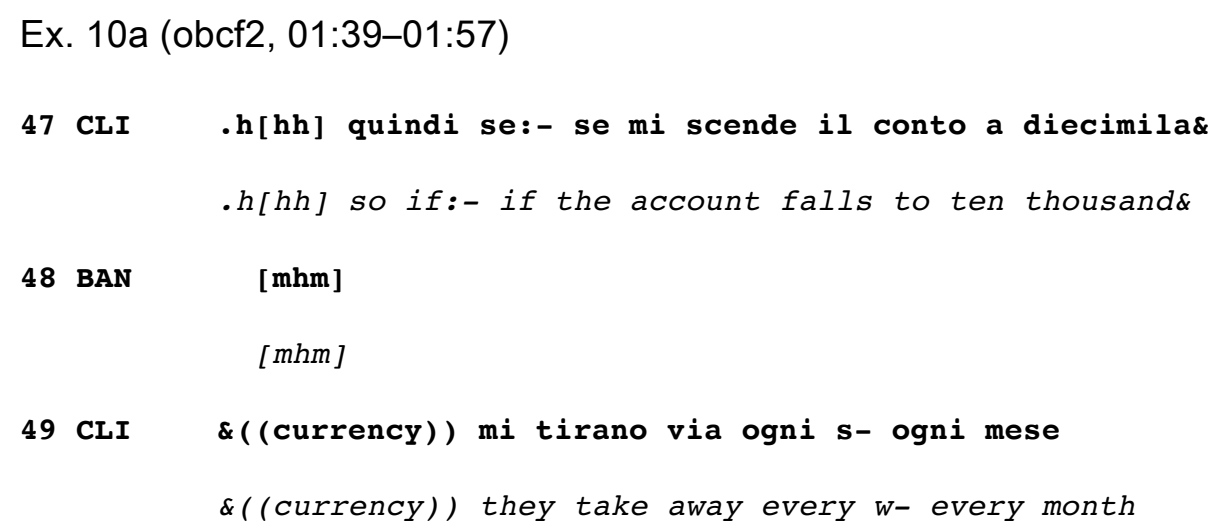


At I. 47-50, CLI recaps what she presents as being the main reason why she wishes to 'take away' the account from the bank. BAN immediately advances a possible solution to that problem by saying that CLI could convert her account to a savings account (l. 51-52), with the benefit of avoiding high activity fees. BAN uses the interrogative construction non le conviene 'wouldn't you want to' (I. 51) and strongly projects an affiliating response. Lines 5152 relate in a specific way to BAN's goal of arranging a meeting with CLI. Indeed, by providing details about CLI's account and the possible benefits to be derived from modifying that account, BAN supplies evidence of why accepting the initial invitation would be a sensible thing to do. If CLI agrees that it would be wise to transform her current account into a savings account, then it will be much more difficult for her to maintain that she is "not interested' (excerpt 4, I. 13-14) in learning about the new bank products. After a lengthy pause (I. 53), CLI produces a turn that has features of dispreference, such as the delayed start, the initial eh: eh 'uh: uh', as well as the following si ma 'yes but' (I. 54). By doing so, CLI affiliates with BAN's idea, but nonetheless displays that her affiliation is problematic. She explains the nature of the problem in the subsequent part of her turn with the words loro non mi hanno mai proposto ... una cosa cosi. 'they have never proposed ... anything like that.' (I. 54-55). Two aspects of this turn are worth noticing. On the one hand, it treats BAN's previous turn as having made a proposal; on the other hand, it presents that proposal as something that 'they' (i.e., not further specified bank assistants) should have done earlier. It is the latter point that BAN orients to when she expresses her being sorry (I. 56). 
The conversation continues for almost one and a half minutes, during which CLI complains about the services the bank provides, in response to which BAN produces multiple displays of empathy. The last excerpt begins after CLI has mentioned her difficulties in understanding bank 'things'.

Ex. 10b (obcf2, 03:14-03:33)

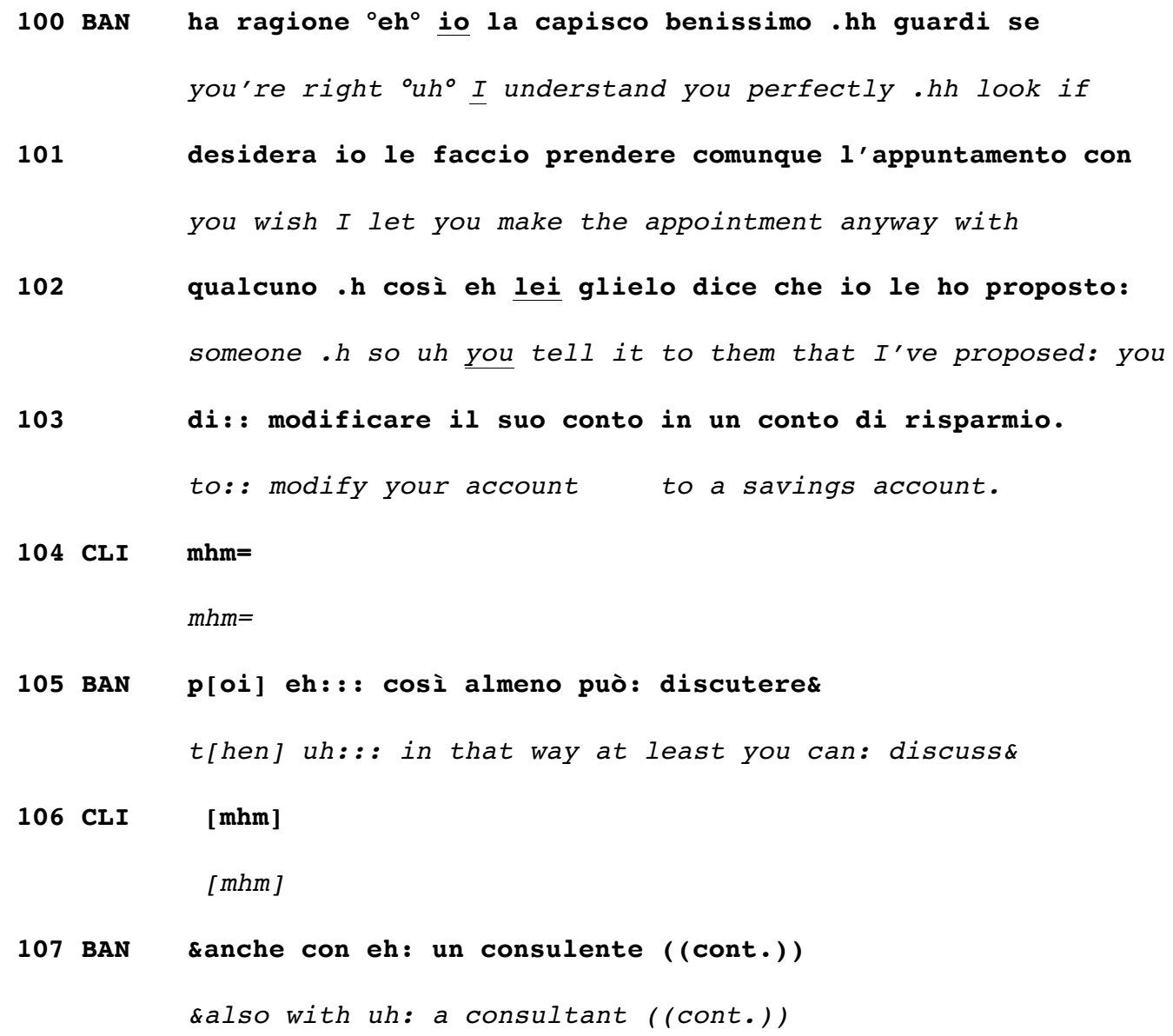

Having once again displayed empathy with CLI's situation (I. 100), BAN makes a further attempt to arrange a meeting. By saying se desidera 'if you wish' (I. 100-101), she provides the opportunity for CLI to respond in a positive or negative way. The subsequent wording io le faccio prendere comunque l'appuntamento 'I let you make the appointment anyway' (I. 101 ) is sensitive to CLl's initial rejection of the invitation (excerpt 4). The adverb comunque is understandable as 'in spite of' (the previous rejection), whereas the use of the definite article in l'appuntamento 'the appointment' hints toward something that has already been talked about. In the continuation of her turn, BAN articulates the upshot of that meeting, namely that CLI 'tells' the consultant about the proposal that BAN has just made to change CLI's account type. At I. 104, CLI produces a $\mathrm{mhm}$, after which BAN further develops the advantages of such a meeting (I. 105-107) while CLI again utters a mhm (I. 106). Whereas on other occasions BANs treat tokens such as $\mathrm{mhm}$ merely as continuers, in this case BAN takes 
CLl's $m h m s$ as affiliating with her plan to arrange a meeting; indeed CLI does not accept the invitation any more overtly than this, but even so BAN starts looking for an appropriate consultant in CLI's area of residence, and the participants will eventually arrange a meeting (data not shown).

\section{Discussion}

I have analyzed cold calls during which bank employees invite existing clients to a meeting at a local branch of the bank. I have identified two techniques or formats that callers employ for this purpose-the formulation format and the solicitation format-and examined the ways in which clients respond to either format. The novelty of this article is its focus on institutional invitations (as opposed to ordinary social invitations). While bank employees may formulate what they are doing as being an invitation, the analyses have shown that they pursue a twofold objective, since they also aim to encourage the client to sign up for specific bank products or services. Bank employees consistently cite the arrangement of a consultation as the primary goal of the invitation, whereas they present the illustration of (new) bank products merely as the purpose of such a meeting. Clients may reject both the invitation and the sales proposal (excerpt 3); they may reject the invitation but accept the sales proposal (excerpt 6); or they may accept the invitation and leave it open whether they will eventually accept or reject the sales proposal (excerpt 10). If clients agree to sign up for specific bank products during the telephone call, bank employees abandon the project of arranging a meeting (excerpt 6). This is evidence that bank employees (but also clients) treat the appointment as dispensable. Clearly, the bank employees' objective of arranging a meeting is in the service of getting clients to sign up for specific services. Hence, in terms of the effectiveness of the call, from the bank employee's perspective, the client's acceptance of new bank services is the primary goal. This shows a significant discrepancy between what bank employees display and what they treat as a successful outcome of the conversation. The question that arises, then, is why is it that bank employees frame their attempts as invitations? The advantage of this practice is certainly that the use of the verb invitare 'to invite' mimics a common action in ordinary social conversation, which creates the standardized relational pair (Sacks, 1972) 'inviter'-'invitee', where the latter enjoys some sort of benefit (Drew, 1984; Clayman and Heritage, 2014; Couper-Kuhlen, 2014). Callers manifestly encode a benefactive stance (Clayman and Heritage, 2014) when they utter institutional invitations. However, when the label of 'inviting' is transposed from the social sphere to an institutional setting, the question of which party benefits from the invitation is manifestly distorted. This is visible in the data analyzed here, but also in other kinds of institutional invitations such as invitations to shop openings, or, more clearly, in payment reminders, which in Italian (but also in French) are commonly phrased as 'inviting' the recipient to send their payment. 
That being so, should we, as analysts, still use the label 'invitation' for the practices observed here? In his analysis of telemarketing conversations in which callers work toward arranging an appointment between a financial adviser and a prospect, Mazeland (2004) observes that callers present the appointment as an offer. Couper-Kuhlen (2014:628, n. 7) stresses that whatever labels we use (e.g., invitation, offer, proposal), these are technical terms employed for the practical purposes of the analysis, whereas participants may use other labels, lay terms, to describe specific actions. This observation should caution us against the methodological and analytical pitfalls in the use of rigid taxonomies of action (see Searle, 1976). The problem of action formation (Schegloff, 2007) and action ascription (Levinson, 2013) is, first and foremost, a members' problem. Analysts have the problem instead of having to use technical terms that capture recurrently observable linguistic and embodied social actions for which vernacular terms may not even exist (see, e.g., Kendrick and Drew's (2016) notion of recruitment). Moreover, since the bank employees pursue a twofold goal, an analysis based on single adjacency pairs would not reveal the subtleties of clients' responses -e.g., as rejecting the invitation while at the same time accepting the sales proposal (excerpt 6). A manifest limitation of this study is the fact that it is based on a small collection of thirteen telephone calls.

\section{Conclusion}

This article started with a description of two social action formats that bank employees employ in cold calls to existing clients. The analysis has shown that the formulation format is followed either by early rejection or late acceptance of the invitation. Conversely, recipients respond to the solicitation format with either early acceptance or late rejection of the invitation. The different ways of responding are sensitive to the way in which callers construct their invitation bit by bit as they pursue a response from recipients: callers may first formulate the invitation (as the reason for the call) and then add the purpose of the invitation and, subsequently, benefits that the call-takers could derive from accepting. Or, they start the conversation by mentioning a biographical event concerning the recipient, the recipient's birthday, (as the reason for the call) and then explain the consequences that this event has for the bank services that the client uses. In other words, in the formulation format the caller first proffers the invitation and then accounts for it whereas, in the solicitation format, the account precedes the invitation.

Different circumstances seem to operate in the two formats: bank employees use the formulation format when they have no empirically verifiable, client-related reason for making the call. In that case, they present what they are doing as being an invitation, and they do so immediately after the opening sequence. Here, the use of the verb 'to invite' in anchor 
position may also serve to prevent possible critical inferences clients could make upon finding out that 'the bank' is calling them (e.g., an overdrawn account). Bank employees use instead the solicitation format when there is an empirically verifiable, client-oriented reason for the call. Reaching a certain age may have consequences for the relationship clients have with the bank. They may, for instance, no longer be entitled to bank accounts with preferential conditions and these will be transformed into 'regular' accounts, should they take no further action. In either case, clients are free to accept or reject the invitation and the services that bank employees are trying to sell them. However, the different circumstances are also addressed by the clients. For instance, clients tend to reject an invitation done with the formulation format early in the conversation and straightforwardly-thereby treating what bank employees are doing as an attempt to sell new services, rather than as an invitation from which they could draw benefits. Rejecting an invitation proffered with the solicitation format demands instead more interactional work and is not done right away-precisely because, among other things, clients are first provided with empirical facts regarding their biography, and this enables them to recognize the potentially benefactive import of the invitation. In either case, clients may display initial acceptance of the invitation, which, however, does not imply any commitment on the client's part. Bank employees treat acceptance as the preferred response to the invitation, and upon acceptance participants start searching for a date on which the meeting could take place. This constitutes, in fact, an opportunity for late rejection of the invitation by clients, who at this point may claim an inability to find a date. Conversely, bank employees treat rejection as a dispreferred response, and upon rejection they make attempts to transform the initial rejection into acceptance.$^{8}$ In other words, initial responses are precisely that, initial, and participants have the possibility of reversing an initial response as the conversation proceeds. Transforming initial acceptance into final rejection is a client's method, whereas converting initial rejection to final acceptance is a bank employee's method. These findings open up new directions for future research on institutional invitations: how are initial accepting/rejecting responses progressively reversed? What do callers 'offer' in pursuit of a response? What practices do we observe in other languages? Awaiting studies based on a larger data set, this article has proposed a preliminary investigation of institutional invitations in Italian cold calls.

\footnotetext{
${ }^{8}$ As Davidson (1990:163) observed for ordinary invitations, "the mere doing of a rejection does not mean that it will be the outcome". Similarly, in their analysis of calls to mediation services, Sikveland and Stokoe (2016:251) show that mediators may "turn [recipients] around from resistance."
} 


\section{Acknowledgements}

I thank two anonymous reviewers and the editors of this special issue for their valuable and constructive comments on previous versions of this article.

\section{References}

Clayman, Steven, Heritage, John, 2014. Benefactors and beneficiaries. Benefactive status and stance in the management of offers and requests. In: Drew, P., Couper-Kuhlen, E. (Eds.), Requesting in Social Interaction. Amsterdam/Philadelphia, John Benjamins, pp. $55-86$.

Conein, Bernard, 1986. Conversation et interaction sociale. Analyse de séquences d'offre et d'invitation. Langages 21 (81), 111-120.

Conein, Bernard, 1987. Quelques formes de l'interprétation de la conversation dans la conversation. In: Conein, B. (Ed.), Lexique et faits sociaux. Lille, Presses Universitaires de Lille, pp. 37-64.

Couper-Kuhlen, Elizabeth, 2014. What does grammar tell us about action? Pragmatics 24 (3), 623-647.

Couper-Kuhlen, Elizabeth, Ono, Tsyuoshi, 2007. "Incrementing" in conversation: A comparison of practices in English, German and Japanese. Pragmatics 17, 513-552.

Davidson, Judy, 1984. Subsequent versions of invitations, offers, requests, and proposals dealing with potential or actual rejection. In: Atkinson, J. M., Heritage, J. (Eds.), Structures of Social Action. Studies in Conversation Analysis. Cambridge, Cambridge University Press, pp. 102-128.

Davidson, Judy, 1990. Modifications of invitations, offers and rejections. In: Psathas, G. (Ed.), Interaction Competence. Washington DC, IIEMCA and University Press of America, pp. 149-179.

Drew, Paul, 1984. Speakers' reportings in invitation sequences. In: Atkinson, J. M., Heritage, J. (Eds.), Structures of Social Action. Studies in Conversation Analysis. Cambridge, Cambridge University Press, pp. 129-151.

Drew, Paul, 1992. Contested evidence in the courtroom cross-examination. The case of a trial for rape. In: Drew, P., Heritage, J. (Eds.), Talk at Work. Interaction in Institutional Settings. Cambridge, Cambridge University Press, pp. 471-520. 
Drew, Paul, Heritage, John, 1992. Analyzing talk at work. An introduction. In: Drew, P., Heritage, J. (Eds.), Talk at Work. Interaction in Institutional Settings. Cambridge, Cambridge University Press, pp. 3-65.

Fox, Barbara, Heinemann, Trine, 2016. Rethinking format. An examination of requests. Language in Society 45, 499-531.

Garfinkel, Harold, Sacks, Harvey, 1970. On formal structures of practical actions. In: McKinney, J. C., Tiryakian, E. A. (Eds.), Theoretical Sociology. New York: Appleton, pp. 337-66.

Heritage, John, Watson, D. Rod, 1979. Formulations as conversational objects. In Psathas, G. (Ed.), Everyday Language. Studies in Ethnomethodology. New York: Irvington, pp. 123-162.

Jefferson, Gail, 1972. Side sequences. In Sudnow, E. (Ed.), Studies in Social Interaction. New York, The Free Press, 294-338.

Kendrick, Kobin, Drew, Paul, 2016. Recruitment. Offers, requests, and the organization of assistance in interaction. Research on Language and Social Interaction 49 (1), 1-19.

Levinson, Stephen C., 2013. Action formation and ascription. In: Sidnell, J., Stivers, T. (Eds.), The Handbook of Conversation Analysis. Malden/Oxford, Blackwell, pp. 103-130.

Mazeland, Harrie, 2004. Responding to the double implication of telemarketers' opinion queries. Discourse Studies 6 (1), 95-115.

Peräkylä, Anssi, Silverman, David, 1991. Reinterpreting speech-exchange systems. Communication formats in AIDS counselling. Sociology 25 (4), 627-651.

Quéré, Louis, 1987. Mise en place d'un ordre et mise en ordre des places. L'invitation comme événement conversationnel. In: Conein, B. (Ed.), Lexique et faits sociaux. Lille, Presses Universitaires de Lille, pp. 101-138.

Raymond, Geoffrey, 2003. Grammar and social relations: Yes/no interrogatives and the structure of responding. American Sociological Review 68 (6), 939-967.

Rossano, Federico, 2010. Questioning and responding in Italian. Journal of Pragmatics 42, 2756-2771. 
Rossi, Giovanni, Zinken, Jörg, 2016. Grammar and social agency: The pragmatics of impersonal deontic statements. Language 92 (4), e296-e325.

Sacks, Harvey, 1972. An initial investigation of the usability of conversational data for doing sociology. In: Sudnow, D. (Ed.), Studies in Social Interaction. New York, The Free Press, $31-74$.

Sacks, Harvey, 1992. Lectures on Conversation. Malden MA, Blackwell.

Sacks, Harvey, Schegloff, Emanuel A., Jefferson, Gail, 1974. A simplest systematics for the organization of turn-taking for conversation. Language 50 (4), 696-735.

Schegloff, Emanuel A., 1986. The routine as achievement. Human Studies 9, 111-151.

Schegloff, Emanuel A., 1996. Turn organization. One intersection of grammar and interaction. In: Ochs, E., Thompson, S., Schegloff, E. A. (Eds.), Interaction and Grammar. Cambridge, Cambridge University Press, pp. 52-133.

Schegloff, Emanuel A., 2007. Sequence Organization in Interaction. A Primer in Conversation Analysis. Cambridge, Cambridge University Press.

Searle, John R., 1976. A classification of illocutionary acts. Language in Society 5, 1-23.

Sikveland, Rein, Stokoe, Elizabeth, 2016. Dealing with resistance in initial intake and inquiry calls to mediation: The power of "willing". Conflict Resolution Quarterly 33/3: 235-354.

Stokoe, Elizabeth, 2013. Overcoming barriers to mediation in intake calls to services: Research-based strategies for mediators. Negotiation Journal 29 (3), 289-314.

Varcasia, Cecilia, 2013. Business and Service Telephone Conversations. An Investigation of British English, German and Italian Encounters. Basingstoke, Palgrave Macmillan. 